hours through the day-for example, quartered paediatric aspirin tablets-would give much more effective aspirin cover than one standard $300 \mathrm{mg}$ aspirin tablet daily, and without any risk of gastrointestinal disturbance.

R D EASTHAM

Department of Pathology,

Frenchay Hospital,

Bristol BS16 1LE

1 Hanley SP, Bevan J, Cockbill SR, Hepinstall S. Differential inhibition by low-dose aspirin of human venous prostacyclin synthesis and platelet thromboxane synthesis. Lancet 1981;i:969-71.

2 de Gaetano G, Cerlett C, Bertele V. Pharmacology of antiplatelet drugs and clinical trials on thrombosis prevention: a difficul link. Lancet 1982;ii:974-7.

3 Cerskus AL, Ali M, Davies BJ, McDonald JW. Possible significance of functional platelets in a population of aspirinreated plateles in vitro and in vivo. Thrombosis Research 1980;18:389-97.

4 Goodman LS, Gilman AG, Gilman A. The pharmacological basis of therapeutics. 6th ed. London: Baillière Tindall, 1980:694.

5 Merino J, Livio M, Rajtar G, de Gaetano G. Salicylate reverses in vitro aspirin inhibition of rat platelet and vascular prostacyclin

6 Pedersen AK, Fitzgerald GA. Dose-related kinetics of aspirin. Presystemic acetylation of platelet cyclo-oxygenase. $N E n g l\}$ Med 1984;311:1206-11

7 Sinzinger H, O'Grady J, Fitscha P, Kaliman J. Extremely-low dose aspirin (one milligram per day) renders human platelets more sensitive to antiaggregation prostaglandins. $N \mathrm{Engl} \mathcal{J}$ Med 1984;311:1052.

8 Jakubowski JA, Stampfer MJ, Vaillancourt R, Deykin D. Cumulative antiplatelet effect of low-dose enteric coated aspirin. Br $\mathcal{F}$ Haematol 1985;60:635-42.

\section{Chronic bronchial sepsis and progressive lung disease}

SIR,-After reading the leading article by $\operatorname{Dr} G M$ Cochrane on chronic bronchial sepsis and progressive lung damage (6 April, p 1026-7) we thought it was worth while to show how methods of diagnostic imaging may be of value in assessing patients with early bronchiectasis, in particular computed tomography. ${ }^{12}$

One particular question was posed: "Can we identify patients with chronic bronchial sepsis of no obvious cause who are likely to develop lung damage by any other means than measuring the elastase in the sputum or by observing irreversible reduction in respiratory function?" Diagnostic radiology may not directly give prognostic information but will in many cases show lung damage at an early or focal stage. We have recently seen two examples.

Case 1-A 36 year old woman had suffered from a constant productive cough for 20 years although chest $x$ ray films had remained normal throughout. The patient had earlier declined to have bronchography. Computed tomography was therefore undertaken (EMI 5005, $13 \mathrm{~mm}$ slices, 20 second generation. Biochemical Pharmacology 1980;29:1093-6.

scanning time). The most recent plain chest $x$ ray film showed no abnormality, but computed tomograms through the bases of the lungs showed considerable thickening of the bronchial walls and dilatation of the bronchi when compared with the adjacent pulmonary arteries (fig 1). These are the appearances of localised bronchiectasis.

Case 2-A 54 year old man was referred because of breathlessness and a chronic productive cough Respiratory function studies, showed severe airflow obstruction. Chest radiographs had shown a widespread pattern of small nodules and linear opacities. Computed tomography (Siemens DRH $4 \mathrm{~mm}$ slices) showed surprisingly severe bronchiec tasis throughout both lungs (fig 2).

These cases show the value of computed tomography when bronchiectasis is suspected but the chest radiograph is not diagnostic. In most cases of gross bronchiectasis chest radiographs will show the abnormality, and a completely normal chest radiograph is unusual. ${ }^{3}$ In the past computed tomography has been, debatably, slightly less sensitive than bronchography in showing the changes of bronchiectasis, but computed tomography is now available in many district general hospitals and with the use of the latest generation of scanners with thin slices, as in fig 2, the resolution and hence sensitivity will probably closely approach those of bronchography.

In view of its lack of morbidity and the ease of obtaining images computed tomography is unquestionably preferable to bronchography as a screening procedure in patients with unexplained chronic productive cough or haemoptysis, and in the latter is complementary to bronchoscopy. Computed tomography can also show bronchial wall thickening that would not be shown by bronchography. The demonstration of the site and extent of pulmonary damage may be valuable when planning surgery and help in physiotherapy with postural drainage. Furthermore, when used in conjunction with serial respiratory function tests repeat scans may help identify those patients with chronic bronchial sepsis who are destined for progressive lung damage.

On some occasions other conditions that can cause chronic purulent sputum or haemoptysis may be shown by computed tomography. These include pulmonary sequestration, carcinoma of the bronchus, and bronchial adenoma. Computed tomography is a technique that is rapidly finding a place in the diagnosis and management of patients with chronic bronchial sepsis.

We thank Drs Hoffman, Anderson, and Laszlo for their help. The illustrations were prepared by the department of illustration, Bristol Royal Infirmary.
Department of Radiodiagnosis

Respiratory Department, Bristol Royal Infirmary, Bristol BS2 8HW
PAUL R GODDARD U A TAJUDDIN

D MCGIVERN
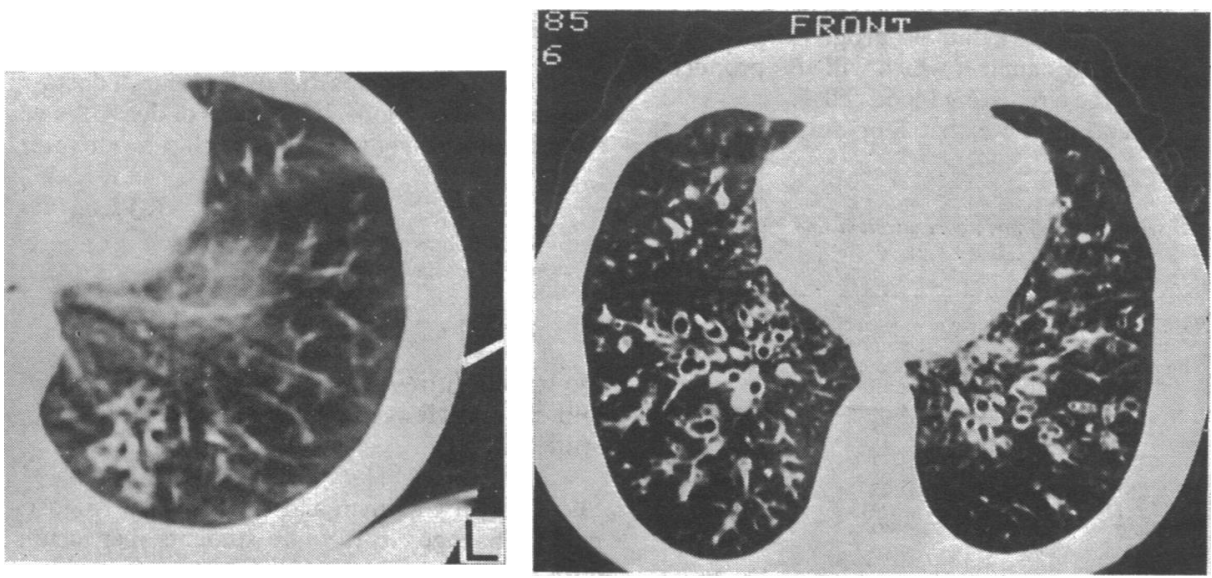

FIG 1 (left)-Computed tomogram of bases of the lungs showing dilated bronchi with thickened walls. FIG 2 (right)-Widespread changes of bronchiectasis.
1 Naidich DP, McCauley DI, Khouni NF, Stitih FP, Siegelman SS. Computed tomography of bronchiectasis. Fournal of Computer Assisted Tomography 1982;6(3):437-44.

2 Osman J, Mootoosamy IM, Reznek RA, Rees RSO, Green M. Computed tomography and bronchiectasis. Thorax 1984 39:688

3 Gudbjerg CE. Roentgenologic diagnosis of bronchiectasis. An analysis of 112 cases. Acta Radiologica 1955;43:209-26.

\section{CSM Update: adverse drug reactions and the} liver

SIR,-We have followed with interest your regular monthly column, CSM Update. However, we were concerned to read (6 July, p 46) that ketoconazole can produce "unsuspected cirrhosis . . . which may at times be recognised only after the drug has been discontinued."

We are currently analysing data from the 82 cases of hepatitis associated with ketoconazole reported from early 1981 to November $1984 .^{1}$ Reports of hepatitis associated with ketoconazole from outside the UK are also available. Although cases of acute hepatitis ${ }^{2}$ and some deaths in hepatic failure ${ }^{3}$ have been reported, we are not aware of any reports of cirrhosis associated with ketoconazole treatment.

Liver injury associated with ketoconazole is reversible on stopping treatment. ${ }^{2}$ Furthermore, the half life of ketoconazole in plasma is short $(75-155 \mathrm{~min}) .{ }^{4}$ This is in contrast to perhexiline and amiodarone, which have half lives of several days ${ }^{56}$ and which have been associated with unsuspected cirrhosis occurring after the drugs have been stopped. In our opinion the statement as it relates to ketoconazole induced liver injury is unsupported by current evidence.

G LAKE-BAKAAR H A CAMERON

Janssen Pharmaceuticals Ltd,

Wantage,

Oxford OX12 ODQ

Committee on Safety of Medicines. Oral ketoconazole and liver damage. Adverse Reaction Series 1985; Jan No 19.

2 Lewis JH, Zimmerman HJ, Benson GD, Ishak KG. Hepatic injury associated with ketoconazole therapy. Analysis of 33 cases. Gastroenterology 1984:86:503-13.

3 Duarte PA, Chow CC, Simons F, Ruskin J. Fatal hepatitis associated with ketoconazole therapy. Arch Intern Med 1984 144:1069-70.

4 Daneshmend TK, Warnock DW, Ene MD, et al. Multiple dose pharmacokinetics of ketoconazole and their effects on antipyrine kinetics in man. $\mathcal{A}$ Antimicrob Chemother 1983;12:185-8 5 Amoah AG, Goula BJ, Parke DV. Single dose pharmacokinetics of perhexiline administered orally to humans. $\mathcal{J}$ Chromatogr 1984;305:401-9.

6 Simon JB, Manly PN, Brien JF, Armstrong PW. Amiodarone hepatotoxicity simulating alcoholic liver disease. $N$ Engl f Med 1984;311:167-72.

${ }_{*}^{*}$ The chairman of the Committee on Safety of Medicines replies below.-ED, $B M \mathcal{H}$.

SIR, - We have not received any reports of cirrhosis associated with ketoconazole and I apologise for this error. The CSM commented on ketoconazole in detail in its adverse reaction warning letter to the profession in January this year.

A GOLDBERG

Committee on Safety of Medicines,

London SW8 5NQ

\section{Idiopathic hypopituitarism in the eldery}

SIR,-We were interested in Dr P E Belchetz's short report (27 July, p 247). As he says, the cause and basic defect are usually unknown. We would like to report, however, a case in which hypopituitarism in an old woman was apparently the result of progressive hypothalamic failure.

The patient was 75 years old when admitted with hypothermia (rectal temperature $28^{\circ} \mathrm{C}$ ) in February 